\title{
Detecting the infrastructural, demographic and climatic changes on macroalgal blooms using cellular automata simulation
}

\author{
$\underline{\text { K. O'Neill }}^{1}$, M. Schreider ${ }^{1}$, L. McArthur ${ }^{2}$ and S. Schreider ${ }^{2}$ \\ ${ }^{1}$ University of Newcastle, Ourimbah Campus, NSW 2258 \\ ${ }^{2}$ RMIT, Australia \\ Email: karen.oneill@,newcastle.edu.au
}

\begin{abstract}
Worldwide, the effects of anthropogenic nutrient loading into estuaries include a shift from sea grass to macroalgae, particularly the "bloom and bust" cycle of the ephemeral Chlorophyta. Macroalgal blooms only occur in spring and summer when rainfall prior to and during this time is low. This study describes temporal and spatial dynamics of nuisance macroalgal blooms in Avoca Lake, an intermittently closed and open lagoon lake (ICOLL) in NSW, Australia and identifies the main factors influencing algal growth in that lagoon.
\end{abstract}

The dynamics are modelled using discrete cellular automata (CA) and a set of algorithms to capture the spread of the blooms. The objective at this stage is to identify the factors that contribute to the spread and ultimately to identify the factors that cause the initial outbreaks. Water temperature, salinity, dissolved oxygen, turbidity and bioavailable nutrients (nitrogen and phosphate) were measured, at weekly intervals, throughout the Lake during the major bloom which occurred in late 2012 as these variables are all considered likely candidates for blooms.

Salinity and light were identified as two most important factors influencing algal growth; blooms always started at the shallow edges of the lake or around seagrass patches where algae attached to seagrass blades were positioned closer to the surface. No bloom occurred during the same period of the previous year when there was a lot more rainfall and much lower salinity in the ICOLL.

Aerial photographs taken on four occasions over this period were digitised to record the extent of macroalgal cover. The CA model is initialised using knowledge of the behavioural dynamics of the algae; notably, that usually they are first observed at the edges of the ICOLL, where the water is warm and the light is good, due to the shallow water level. Later models will be initiated with observed data at the start of the 2012 bloom and validated by comparison of the simulated data with the observed.

The CA model presented in this work is a further extension of the model developed by the authors. The discrete-Laplacian description for biomass provided a method to describe the spread and growth of algae, which incorporated currents, seagrass distribution, water depth and other parameters. The results of the present study highlight that when developing a model to predict the occurrence, spread and duration of macroalgal blooms in this ICOLL; such a model must include detailed data on dissolved oxygen, turbidity, salinity and nutrients. Additional complexity arises from the periodic opening of the ICOLL to the ocean. This also influences algal biomass dynamics, and the model will assist with determining the effect of the opening on the dynamics.

Keywords: Macroalgal bloom, Avoca ICOLL, cellular automata, parameter optimisation, simulation modelling 


\section{INTRODUCTION}

The shift from seagrass dominated estuaries to macroalgal dominance is a world-wide trend caused by eutrophication (Kemp et al., 1983; Duarte, 1995; Short et al., 1995; Short \& Wyllie-Echeverria, 1996; Irlandi et al., 2004). Effects of anthropogenic nitrogen loading are seen as the most pervasive world-wide human impacts on estuaries (Short et al., 1995). Higher nutrient loads benefit opportunistic benthic algae and drift algae over seagrasses and they become the dominant macrophytes in the system.

The dominance of ephemeral algae occurs due to their finely structured thalli with high capacity for both uptake of nutrients and growth (Hauxwell et al., 2003). High density algal mats can prevent light from reaching seagrass and cause hypoxia through respiratory processes. Drift algae have 'boom and bust' cycles and thus, when in decline the sediment is supplied with rapidly decomposing organic material (Pederson et al., 1997). Although green algae (Chlorophyta) are the main contributors to macroalgal blooms, some reds (Rhodophtya) and browns (Phaeophyta) have also been associated with macroalgal blooms in seagrasses and coral turfs. Contrary to popular beliefs, these algal blooms are not harmful to humans. They are, however, unsightly, have a strong smell and reduce opportunities for aquatic leisure activities causing a lot of distress for local residents.

Generally, nitrogen, phosphorus and silica are the main nutrients used for macrophyte growth in estuaries. The processes of nitrogen fixation, nitrification, reduction and denitrification are activated via microorganisms and chemical reactions. Nitrogen fixation is now more than $50 \%$ higher than in preindustrial 1850, thus potential accumulation of excess fixed $\mathrm{N}$ can cause nitrate pollution and microbial production of $\mathrm{N}_{2} \mathrm{O}$ gas.

Phosphorus binds with carbon in living organic matter, so the more phosphorus becomes available the more biomass is formed. Oxygen is removed from the system after the die-off of the blooming algae during the process of rotting of tissues. Nitrogen and phosphorus compounds accumulate in the sediments and these nutrient loads can have significant influence on the water quality of shallow lakes including the formation of algal blooms. Most of the sediment nutrients had been assumed to be unavailable for plant growth (i.e. bound within sediment), but it is now recognised that the length of time that the nutrients in the sediment can become biologically available can range from a decade to more than 100 years (Webster and Wallace, 2000).

Although nutrient composition and nutrient fluxes for ICOLLs (intermittently closed and open lagoon lakes) are generally poorly understood, the contribution of sediment nutrient to algal blooms is widely recognised and fluxes to the water column are sufficient to supply a large algal bloom in as little as 10 days, given that other environmental conditions are met. The Gosford Council periodically open the mouth of the lagoon to the ocean in order to reduce the water level after heavy rains. The effect of the periodic opening of the entrance is not known but may be a major contributor to macroalgal growth. This is another factor that will be investigated by the model simulations.

The extent of macroalgal coverage is also dependent upon light availability for photosynthesis. The algae under study primarily grows on the substrate, thus the clarity of the water will influence the light availability. Hence water depth and availability of suitable substrate, such as is found at ICOLL edges, within fringing wetland vegetation, and among submerged aquatic vegetation, are all important features when determining the extent to which macroalgae can cover the ICOLL.

Thus, we propose that nutrient levels, rainfall, substrate conditions and temperature all contribute to algal coverage. The aim of this study is to identify and quantify the parameters that trigger an algal bloom on Avoca Lagoon using cellular automata models, and this paper describes the methods that will be used and the initial findings. The model consists of a grid of cells, representing $10 \times 10 \mathrm{~m}^{2}$ square areas that cover the lagoon. Each cell is assigned a 'state' indicating the presence or absence of the algae, 1, 0 respectively. At each time step, the state of each cell is updated, according to a set of rules related to the conditions described above, and the state of surrounding cells. This is a variation of the Game of Life introduced by Conway, (Gardner, 1970), and described in detail in McArthur et al. (2006) and Dunn et al., (2011).

\section{STUDY AREA}

Avoca ICOLL is located about $90 \mathrm{~km}$ north of Sydney, NSW, Australia -33.47: 151.43 (Figure 1). The catchment to Avoca ICOLL is within the Gosford City Council Local Government area and covers approximately $11.6 \mathrm{~km}^{2}$ while the surface area of the lagoon is approximately $0.63 \mathrm{~km}^{2}$. Much of the upper catchment is rural land, predominantly farm land or undeveloped forest. The lower slopes in the vicinity of the lagoon contain significant urban development. The lake is roughly star-shaped, comprising four irregular arms and has a considerable area of wetlands around its perimeter (Figure 1). Bareena Island is 
approximately in the centre of the lake. The main tributary to the lagoon is Saltwater Creek which enters the lagoon on the western side and drains an area of $6.7 \mathrm{~km}^{2}$, almost $60 \%$ of the catchment. Other tributaries all have catchment areas of less than $1 \mathrm{~km}^{2}$ and enter the lagoon via the other arms. The bed level of the lagoon generally varies from 0.0 to 1.5 metres (above mean sea level) AHD (Australian Height Datum, which is equivalent to mean sea level of 0 ) although there are dredge holes down to -4.0 AHD. The outlet to the ocean through Avoca Beach is generally closed by the beach berm and water levels inside the lagoon are not usually influenced by ocean tides (GCC, 2010).

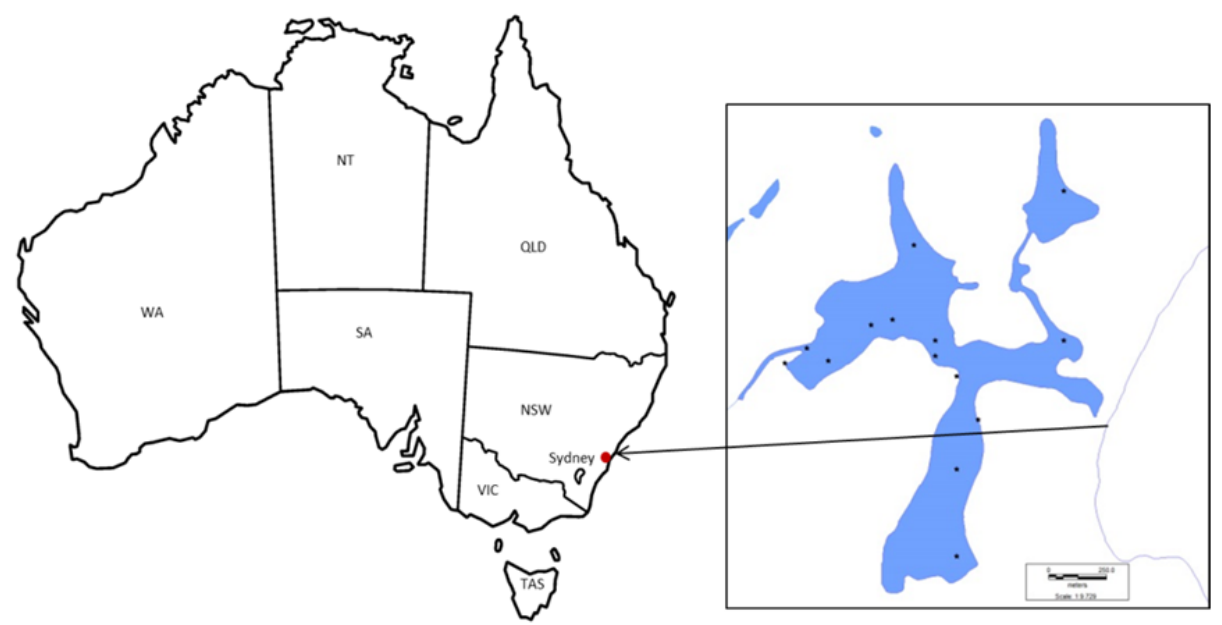

Figure 1. Location of study site

\section{METHODS}

\subsection{Water Quality Sampling}

Various sites during Spring-Summer of 2012 within the ICOLL were sampled for physico-chemical variables (dissolved oxygen, conductivity, temperature, $\mathrm{pH}$ and turbidity), which were measured using a YeoKal ${ }^{\mathrm{TM}}$ (water quality analyzer). A further sample of water was collected from each site to test for Nitrate-Nitrogen and Orthophosphate using a La Motte ${ }^{\mathrm{TM}}$ colorimeter. Nitrate was measured using the Zinc Reduction method that estimated nitrate-nitrogen content in the range of 0.0 to $60.0 \mathrm{ppm}$. Phosphate-Low range was measured using the Ascorbic acid reduction that measures $\mathrm{P}$ concentrations in the range of 0.00 to $3.00 \mathrm{ppm}$ Orthophosphate. The sampling was generally done at the same sites over this period reducing the spatial variation from the data.

\subsection{Mapping algal distribution during a bloom}

Aerial photographs were taken with a Nikkon D3100 SLR Camera with a polarising lens from a plane at an average height of 1600 metres on four occasions, on October 17, October 30, November 15 and December 2 2012. GIS data files obtained from Gosford City Council (GCC) were used with the digitised aerial photographs for GIS mapping to determine spread of macroalgal bloom during this time. Using data provided by GCC, NSW Department of Lands, digitisation of Avoca ICOLL was made using Excel and ArcGIS (V10) software (ESRI Inc.). The raw data included over 30,000 points and, thus, were modified in Excel to better suit ArcGIS. ArcCatalog and ArcMap (V10) (ESRI Inc.) were used to create a visual representation of the outline of Avoca ICOLL.

The ICOLL was partitioned into cells of $10 \mathrm{~m}$ by $10 \mathrm{~m}$. The resulting grid was superimposed over the perimeter of the extracted outline of the ICOLL in ArcGIS. Excel was used to create a table of " $x$ " and " $y$ " values and a third column, "a", indicating the presence (1) or absence (0) of algae. The data used to identify presence of algae were generated by examining the aerial photographs. The shaded maps from each time period were manually compared to their $\mathrm{x}$ and $\mathrm{y}$ cells. Separate coordinate tables were created for each four dates of aerial photographs. The third column was sorted in Excel to omit those corresponding to land. The cells containing algae were now updated to 1 to indicate the presence of biomass. To ensure that the shaded maps had been transcribed properly the data sets were plotted in Excel and compared to the original photograph and shaded maps to ensure accuracy. 


\subsection{Modelling}

The model is a cellular automata discrete model, which is based upon a model developed by McArthur et al., (2006) to determine the spread and growth of Caulerpa taxifolia, which is also an alga. The model divides the area into cells of uniform size, and allocates a state depending on what the cell contains. In the current model the state can be -1 , land, 0 no algae, or 1 indicating the presence of algae. Once the model is initialised, a set of rules is applied which determines the state of each cell after each timestep.

The Avoca Lagoon model does not behave in the same way, and the factors that influence the growth are yet to be determined. The model presented here, is based upon a simple algorithm that initiates the algae around the edges of the south arm and two cells in the extreme west of the west arm. The spread of the algae after several timesteps, based upon a simple rule that states:

1. If $\operatorname{cell}(\mathrm{i}, \mathrm{j})=0$, and

2. The sum of the biomass in the surrounding cells is greater than some threshold $p$, then

3. $\operatorname{Cell}(\mathrm{i}, \mathrm{j})=1$

4. Otherwise cell(i,j) stays the same.

This simple rule is based upon Conway's Game of Life, and allows growth if neighbour cells contain the algae, and does not if they are clear.

The model at this stage is being validated by comparison with the aerial photographs of the lagoon at peak bloom in December, and the parameters of growth and spread are adjusted accordingly. For this reason, the model is not yet realistic, but indicates that with further input, once the important parameters are identified, accurate simulation can be achieved.

The model was programmed in the computer package MATLAB (MathWorks Inc.) and required an input of 3 columns - the $\mathrm{x}, \mathrm{y}$ coordinates of cells and the corresponding presence or absence of the bloom, 0 or 1 . The ICOLL was partitioned into a grid of $10 \times 10 \mathrm{~m}$ cells.

The model is initiated by spontaneous appearance of algae along the edge of the lagoon. Given an optimised set of conditions, the algae will grow, subsequently die and then the tissue rises to the surface as it decomposes. The algae grow where the light conditions are sufficient for active photosynthesis. The presence of seagrass may encourage algal growth by providing the surface for the attachment. Algae that are attached to seagrasses are therefore higher in the water column and can take advantage of available light, especially in deeper areas.

The CA model is designed to encapsulate both the spread and growth of the algae, but in order to do this the factors that drive these phenomena have to be identified. Data have been collected over the 2012 spring outbreak, and include the early stages, pre-peak, peak and decline of the bloom. The bloom began in September and was virtually gone by the end of December. The intention is to initiate the model using data assuming algal growth is initiated at the edges of the ICOLL (with the exception of Bareena Island; Figure 1) and validate the model with the four subsequent data sets. In addition, the previous year (2011) represents a set of data for the null case as no bloom occurred.

\section{RESULTS}

\subsection{Water quality and mapping during spring-summer macroalgal bloom 2012}

Total monthly rainfall was higher in 2011than in 2012 with the exception of January and February 2012.Total annual rainfall for March to December was $1640 \mathrm{~mm}$ for 2011 and $861 \mathrm{~mm}$ for 2012. With January and February excluded from the analysis for 2011 data total monthly rainfall was significantly higher than in $2012(t=2.855, p=0.005)$. In fact, total monthly rainfall from March (except for June when 2011 and 2012 had similar rainfall) to December 2011 was on average $100 \mathrm{~mm}$ higher than the corresponding months of 2012 .

Avoca ICOLL was monitored weekly throughout August and September 2012 to capture the start of the bloom. Isolated patches of macroalgae were first observed at the end of September at the edges of the lake where fringing vegetation was present. These areas included the edges west and east of the bridge, around the Melaleuca sp. and Casuarina sp. stands near the playing field and the edges of the southern arm. The bloom had covered large areas of the southern arm of the ICOLL in October (Figure 2) with the seagrass, Ruppia megacarpa, present in large meadows throughout this arm. In other areas of the ICOLL the bloom had spread inward from the edges towards beds of Zostera capricorni by November. In some areas the 
bloom had started to collapse in November and was almost over by mid-December 2012. The most abundant macroalgae observed during the bloom were Cladophora sp., Enteromorpha intestinalis and Chaetomorpha sp. During the 'boom' stage, these species were bright green but when in 'bust' they first appeared to bubble at the surface and then turned brown (Figure 3).

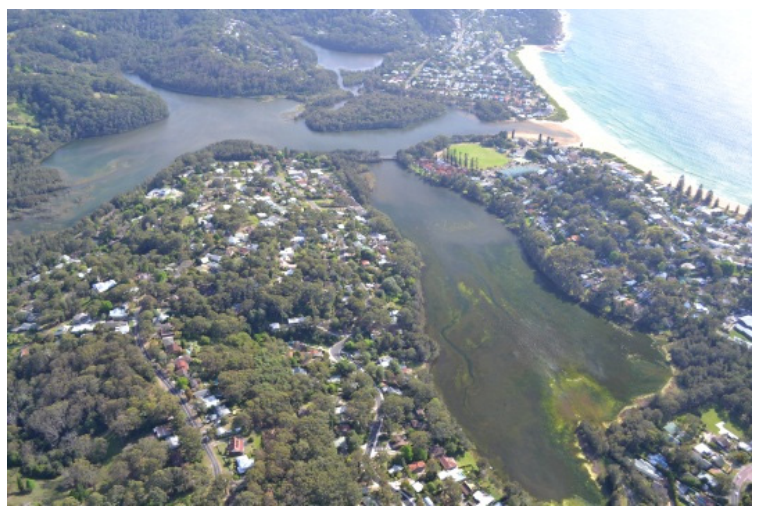

Figure 2. Aerial photo of Avoca ICOLL with the southern arm in the foreground showing extensive algal coverage.

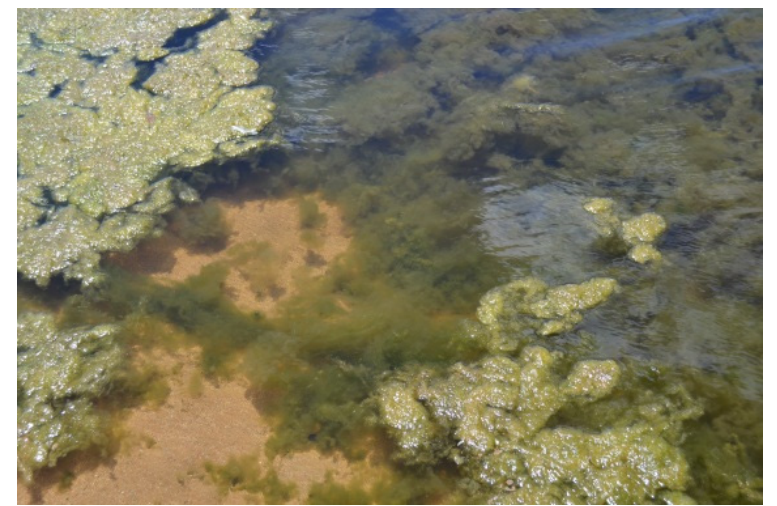

Figure 3. Decomposing bloom at entrance of ICOLL. It can be seen here that the live algae grows on the substrate and once it dies, floats to the surface.

During the spring-summer macroalgal bloom of 2012 water temperature remained within the range of 16 to $30^{\circ} \mathrm{C}$. With the exception of two measurements at the end of September 2012 salinity remained within the range of 15 to $20 \mathrm{ppt}$ and $\mathrm{pH}$ was between 6 to 9 . Dissolved oxygen levels declined from approximately 10 $\mathrm{mg} / \mathrm{L}$ in September to less than $4 \mathrm{mg} / \mathrm{L}$ during November and December 2012. Turbidity increased from below 10 NTU at the start of the macroalgal bloom to over 30 NTU during December 2012 (Figure 4). During September and October nitrates were higher than phosphates, however after this time phosphates increased up to six fold whilst nitrates decreased to levels below $0.2 \mathrm{mg} / \mathrm{L}$ (Figure 5).

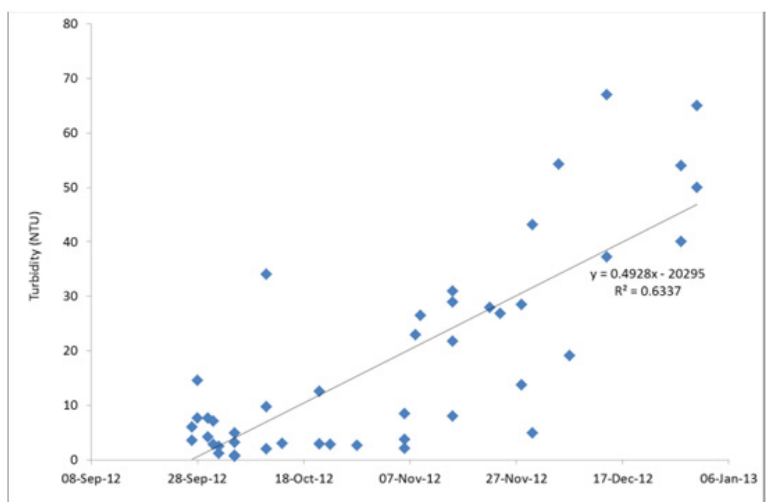

Figure 4. Water column turbidity (NTU) over the macroalgal bloom of 2012. The data points represent different sites.

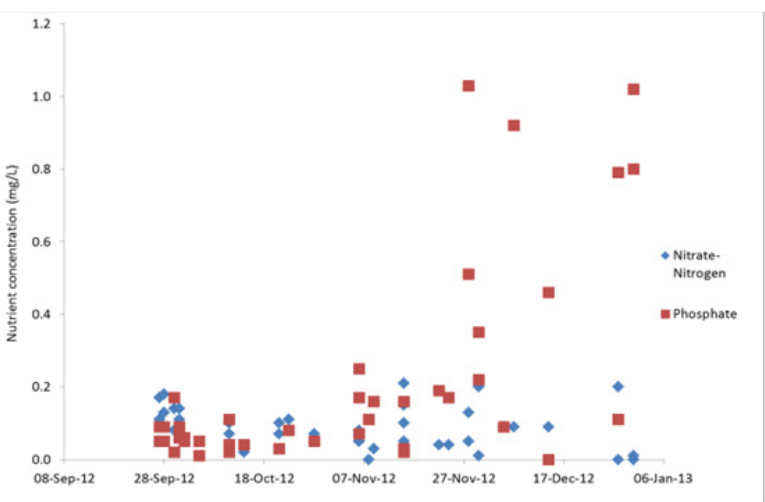

Figure 5. Water column nutrients from various sites over the macroalgal bloom of 2012 .

\subsection{Modelling}

The perimeter of the southern arm of the ICOLL was initiated with and run through the MATLAB simulation model (Figure 6) and the result of a trial simulation run is shown in Figure 7. The initial model run has simulated a spread close to the observed effect, but this is due mostly to perturbation of the parameters without any basis in explicit knowledge of the values. The future of the project lies in the acquisition of information regarding as many as possible external factors that inhibit or encourage the growth of the algae. 


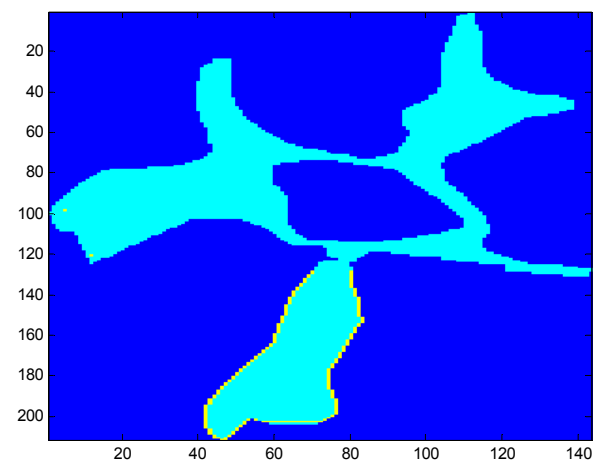

Figure 6. Initiation for the spread of algae.

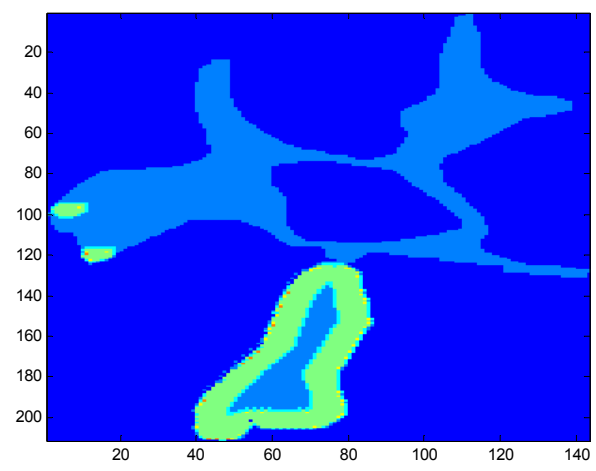

Figure 7. Trial simulation run.

\section{DISCUSSION}

Although results from GCC water quality monitoring were not included in this paper, salinity was lower during September to December 2011 than in the corresponding period for 2012 (Gosford City Council, 2012), which might explain the absence of algal bloom in 2011. Salinity affects ionic concentration, density of seawater and osmotic pressure; thus, when salinity is outside intermediate levels macroalgal cell wall membranes can be compromised. In years of high precipitation characterised by a significant increase of freshwater input into the Mondego estuary in west Portugal, no Enteromorpha intestinalis blooms were observed even though it is an eutrophic estuary with seasonal macroalgal blooms (Martins et al., 1999). The laboratory experiments showed the highest growth rates for E. intestinalis at salinities between $15-20$ psu (Martins et al., 1999). Maximum growth and nutrient uptake were significantly higher at intermediate salinity levels $\sim 20$ psu in Ulva pertusa experiments in south-east Korea (Choi et al., 2010).

Changes in rainfall associated with El Nino and La Nina or major storms affect both the timing and magnitude of blooms. During the El Nino periods correlated with reduced algal blooms and major blooms occurred during low rainfall La Nina periods (Philips et al., 2007). An indirect, but important, consequence of high rainfall must also include the greater number of cloudy days and the subsequent reduction of light available for submerged aquatic vegetation (SAV). High rainfall increases the volume and depth of water in the ICOLL thus decreasing light availability for SAV. Avoca ICOLL is artificially opened to the sea when water depth limits are reached and was artificially opened five times during 2011. GCC open the entrance to prevent flood mitigation. When ICOLLs are open they become tidal with seawater moving into and out of the estuary with the daily tidal cycle. Frequent openings can lead to increased exposure and death of SAV and consequent increased risk of low dissolved oxygen, which can cause fish kills. The death of SAV and increased exposure of sediments to the air may result in release of gases such as hydrogen sulfide (with a foul smell). At the same time, frequent openings may prevent blooms from occurring by draining water from the lake.

No macroalgal bloom occurred in 2011, suggesting that high rainfall that year led to the decreased salinities and, consequently, unfavourable conditions for algal growth. Consequences of high rainfall include not only lower salinity but increased turbidity (due to input of sediments from catchment) and increased water depth (less available light). The lower rainfall in 2012 resulted in lower turbidity and water depth, thus greater available substrate for macroalgal growth. The ICOLL was neither naturally breached nor artificially opened to the ocean during 2012. The macroalgal bloom started in September of 2012; macroalgae were present around the edge of the ICOLL and on seagrasses. The south-eastern arm has vast Ruppia meadows over most of the area, is shallow (less than $1 \mathrm{~m}$ ) and had the largest macroalgal coverage.

After the bloom reaches some biomass threshold it crashes, which is what happened in December 2012. After the death of that biomass a lot of oxygen is removed from the water. Under reducing (anaerobic) conditions caused by massive phosphorus-induced algal blooms, phosphorus is released from the sediment to the overlying water. Available phosphate increased during the expansion of the bloom and water nitrogen decreased to zero in some instances, most likely uptaken by the algae. Nitrate-Nitrogen in the water column was higher at the start of the spring bloom than available phosphate. Fast-growing macroalgae such as Chaetomorpha sp. and Cladophora sp. are known to be able to exploit the dissolved Nitrate-Nitrogen that is in high concentration in the water column (Valeila et al., 1992, Peckol at al., 1994). 
O’Neill et al.., Detecting the infrastructural, demographic and climatic changes on macroalgal blooms

The water quality data collected during the macroalgal bloom of 2012 suggest that rainfall, water depth, turbidity and presence of submerged aquatic vegetation are the most important factors controlling the macroalgal bloom and the extent to which it can spread and, thus, should be the main parameters used by a model.

The development and validation of this model will be able to assist the Gosford City Council in their efforts to understand the triggers that initiate an algal bloom, and thus increase their ability to reduce or eradicate the problem. Further development of the model will see inclusion of the most relevant factors, identified through this study, that contribute to the spread of the bloom once it has been started. The algorithm will be improved so that the simulated spread more close resembles the observed spread. This will be achieved once data from the next bloom has been collected.

\section{Acknowledgements}

This project was funded by Gosford City Council Ecological Research Grant. The authors would also like to thank students: Nick Edsall, Sharmila Muruganandam, Sarah Oakes and Victoria Wielgosz from RMIT University for development and implementation of the cell digitization technique.

\section{REFERENCES}

Choi, T.S., Kang E.J., Kim, J. and Kim, K.J. (2010) Effect of salinity on growth and nutrient uptake of Ulva pertusa (Chlorophyta) from an eelgrass bed, Algae 25(1): 17-26.

Duarte, C.M. (1995) Submerged aquatic vegetation in relation to different nutrient regimes Ophelia 41: 87112.

Dunn, J.M., McArthur, L. and Schreider, S. (2011) Plant biomass and nutrient dynamics: modelling blooming phenomenon. In: Proceedings of the 19th International Congress on Modelling and Simulation, MODSIM2011, Perth, Australia, 12-16 December 2011.

Gardner, M. (1970) Mathematical Games - The fantastic combinations of John Conway's new solitaire game life. Scientific American 223: 120-123.

GCC, (2010) Gosford City Council, Avoca Lagoon. Online: viewed March 2013, URL: http://www.gosford.nsw.gov.au/environment/education/documents/fact-sheets-2/avoca.pdf

Hauxwell, J., Cebrian, J., Valiela I (2003) Eelgrass Zostera marina loss in temperate estuaries: relationship to land-derived nitrogen loads and effect of light limitation imposed by algae Marine Ecology Progress Series 247: 59-73.

Irlandi, E.A., Orlando, B.A. and Biber, P.D. (2004) Drift algae-epiphyte-seagrass interactions in a subtropical Thalassia testudinum meadow Marine Ecology Progress Series 279: 81-91.

Kemp, W.M., Boynton, W.R., Stevenson, J.C., Twilley, R.R. and Means, J.C. (1983) The decline of submerged vascular plants in upper Chesapeake Bay: summary of results concerning possible causes Marine Technology Society Journal 17:78-89.

Martins, I., Oliviera, J.M., Flindt, M.R. and Marques, J.C. (1999) The effect of salinity on the growth rate of the macroalgae Enteromorpha intestinalis (Chlorophyta) in the Mondego estuary (west Portugal), Acta Oecologica 20 (4): 259-265.

McArthur, L.C., Schreider, S. Tim Glasby, T. and Alizadeh Shabani, A. (2006) Modelling the spread of Caulerpa taxifolia in Lake Conjola, southern NSW. In Proceedings of the 15th IASTED International Conference on Applied Simulation and Modelling, 2006. June 26-28, 2006, Rhodes, Greece.

Pederson, M.F. and Borum, J. (1997) Nutrient control of estuarine macroalgae: growth strategy and the balance between nitrogen requirements and uptake Marine Ecology Progress Series 161: 155-163.

Philips, E.J., Hendrickson, J., Quinlan, E.L. and Cichra, M. (2007) Meteorological influences on algal bloom potential in a nutrient-rich blackwater river Freshwater Biology 52: 2141-2155.

Short, F.T., Burdick, F.M. and Kaldy, J.E. (1995) Mesocosm experiments to quantify the effects of eutrophication of eelgrass, Zostera marina Limnol. Oceanography 40: 740-749.

Short, F.T. and Wyllie-Echeverria, S. (1996) A Review of Natural and Human-induced Disturbance of Seagrasses Environmental Conservation 23(1):17-27.

Webster, I.T. and Wallace, B. (2000) Further analysis of sediment core samples collected in the Gippsland Lakes CSIRO Land and Water. Online: viewed March 2013, URL: http://www.gcb.vic.gov.au/publications/csiro/Assorted.pdf 